\section{Waleed K. Jawad \\ Production and Metallurgy Engineering Department, University of Technology Baghdad, Iraq}

\section{Ali T. Ikal \\ Production and Metallurgy Engineering Department, University of Technology Baghdad, Iraq engaliomary@yahoo.com}

Received on: 25/02/2019 Accepted on: 17/05/2019 Published online: 25/08/2019

\title{
Effect of Radial Clearance on Stress and Strain Distribution in the Astral Deep Drawing
}

\begin{abstract}
In this paper, an astral die was designed and constructed to produce an astral cup in the deep drawing operation by experimental work and numerical simulation. The influence of radial clearance on drawing load, cup high, the distribution of stress, strain and thickness along the side wall, minor and major axis were also studied. The deep drawing process was carried out to produce an astral cup with an inner dimension of $(41.5 \mathrm{~mm} \times 34.69 \mathrm{~mm})$, and $(30 \mathrm{~mm})$ height drawn from a blank sheet with a thickness of (0.7) and diameter (80) made of low carbon steel. A commercial program (ANSYS18.0) was used to perform the numerical simulation. Three types of radial clearance equal to $\left(1.1 t_{0}, 1.2 t_{0}\right.$, and $\left.1.3 t_{0}\right)$ are used to investigate the influence of radial clearance. It was found that the maximum value of the drawing load $55 K N$ ) recorded with radial clearance equal (1.1t $t_{0}$. The process of a squeeze in the wall that occurred with the radial clearance (1.1t $\left.t_{0}\right)$ due to the difficulty of the flow of the metal to be exposed to maximum tensile stress. The maximum effective stress $(674 \mathrm{MPa})$ and strain (0.973) were recorded with the clearance of (1.1t $\left.t_{0}\right)$ at the minor axis.
\end{abstract}

Keywords- deep drawing of the astral shape, stress and strain distribution, radial clearance

How to cite this article: W.K. Jawad and A.T. Ikal, "Effect of Radial Clearance on Stress and Strain Distribution in the Astral Deep Drawing," Engineering and Technology Journal, Vol. 37, Part A, No. 8, pp. 332-340, 2019.

This is an open access article under the CC BY 4.0 license http://creativecommons.org/licenses/by/4.0

\section{Introduction}

The deep drawing operation is utilized in industrial sheet metal forming operations in which a blank sheet of metal is drawn into a specific shape such as conical, box, cylindrical and oval or any shape. The deep drawing is a very complex process. It is influenced by several factors like die radius, the radial clearance between the die and punch, die fillet radius, punch profile radius, lubrication type, press speed, and the material characteristics [1]. Several studies dealt with the influence of some variables on the deep drawing operation, especially the effect of the radial clearance to obtain a product with minimal defects. Padmanabhan et al. [2] researched the influence of die fillet radius, the friction between the tool and blank sheet and blank holder pressure on the deep drawing operation of the axi-symmetric cup using the finite element model simulation with Taguchi technique. It was found that the die fillet radius $(89.25 \%)$ has a major effect on the deep drawing operation, followed by the friction coefficient $(6.37 \%)$ and blank holder pressure $(4.55 \%)$. The effect of die profile radius, blank thickness, punch profile radius, clearance between punch and die on thinning and thickness allocation in the deep drawing operation was searched by Zein et al. [3]. The results show that the clearance between punch and die is recommended to be higher than the blank thickness. If the radial clearance is not large sufficient, thinning or ironing occurs. The die profile radius is recommended to be ten times the blank sheet thickness. The punch profile radius is recommended to be higher than six times the blank sheet thickness. Reddy, et al. [4] discussed the influence of various parameters such as punch fillet radius, die fillet radius and blank holder pressure. The results reveal that the greatest influence on the thinning ratio in the deep drawing is contributed from the blank holder force, while the second greater influence comes from the punch fillet radius. The blank holder pressure $(56.98 \%)$ was the most significant factor followed by punch fillet radius $(30.12 \%)$ and the least effect $(12.90 \%)$ was with die fillet radius. Ameen and Abdulridha [5] studied the effect of radial clearance and blank sheet thickness on distribution stress and strain in elliptical deep drawing operation without the blank holder. The results indicate that the radial clearance between the die and punch $(1 \mathrm{~mm})$ gives high drawability and the product was without wrinkling but has higher earing, while clearance between the die and punch $(0.92 \mathrm{~mm})$ gives the best result in elliptical deep drawing operation without the blank holder. Jawed and Salman [6] investigated the effect of wall corner radii of the die on the deep drawing process of the hexagonal cup using numerical simulation and experimental. The results show that the greatest thinning occurs in the minor axis of the hexagonal cup when used wall corner radius of die equal to $(0.7 \mathrm{~mm})$ due to 
greatest stretching of the metal along the corner radius. The best strain and thickness distribution over all zones in the produced cup obtained when using the wall corner radius of die that equals to $(4 \mathrm{~mm})$. The influence of radial clearance on the thickness strain, the maximum amount of deep drawing force and the maximum thinning and the total consumed work was studied by Zaid et al. [7]. The total consumed work was influenced by the radial clearance particularly when it is lower than the blank sheet thickness i.e. the case known as ironing phenomena. Mahmoodi and Sohrabi [8] researched the effects of punch fillet radius, die fillet radius, the clearance between a die and punch, layer arrangement, and blank holder pressure on the square-shape deep-drawing operation. Results have shown that the parameter exerting the highest influence on thinning was punch fillet radius, followed by a layer arrangement. Blank holder pressure had the greatest effect on the wrinkle height. Choubey et al. [9] researched the influence of radial clearance, half-cone angle and die and punch corner radius, on the deep drawing of conical and cylindrical shapes without blank holder using a conical die. The distribution of thickness of the cup was investigated using a simulation to determine the optimal operation design, and to determine the distribution of thickness and radial stress. Nejad et al. [10] studied the influence of the coefficient of friction and punch fillet radius on requiring drawing load and thinning in the deep drawing process. It was illuminated that the coefficient of friction does not influence the drawing load. Also, the coefficient of friction was the most important factor in thinning.

\section{Numerical Simulation}

An astral cup has eight vertices concave and convex with inner dimensions $(41.5 \mathrm{~mm} \times$ $34.69 \mathrm{~mm})$, and $(30 \mathrm{~mm})$ height was selected for detailed numerical simulation of deep drawing operation. In the present study, a commercial ANSYS mechanical APDL 18.0 is used to model the deep drawing operation. The element type SOLID 185 is used for simulating the blank sheet material. The materials used namely low carbon steel. Low carbon steel has a nonlinear inelastic anisotropic behavior. The solid modeling is used to generate automatically defining the shape geometry of the model, the key points, lines, area, and volume then meshing. The automatic contact technique was used to simulate the complex interaction between the blank sheet and the tooling set. Target element TARGE170 is used to represent the rigid tools; punch, dies and blank holder, while contact element CONTA174 is used to represent the deformable blank sheet. The punch moves down at the constant speed $(100 \mathrm{~mm} / \mathrm{min})$ during the drawing operation and the die is stationary. The friction coefficient at the blank sheet-tools interface to be the same and constant $(\mu=0.1)$ and the blank holder is controlled with the constant force of $(3 \mathrm{kN})$. The punch moved along the y-axis at a fixed speed $(50 \mathrm{~mm} / \mathrm{min})$ and the die was stationary during the drawing process. The blank sheet was fixed on the blank holder moving in the $\mathrm{x}$-axis direction as shown in Figure 1. Three types of radial clearance equal to $\left(1.1 t_{\circ}, 1.2 t_{\circ}\right.$, and $\left.1.3 t_{\circ}\right)$ are used to study the influence of radial clearance on effective stress. The Sequential stages of producing the astral cup using the numerical simulation are shown in Figure 2.

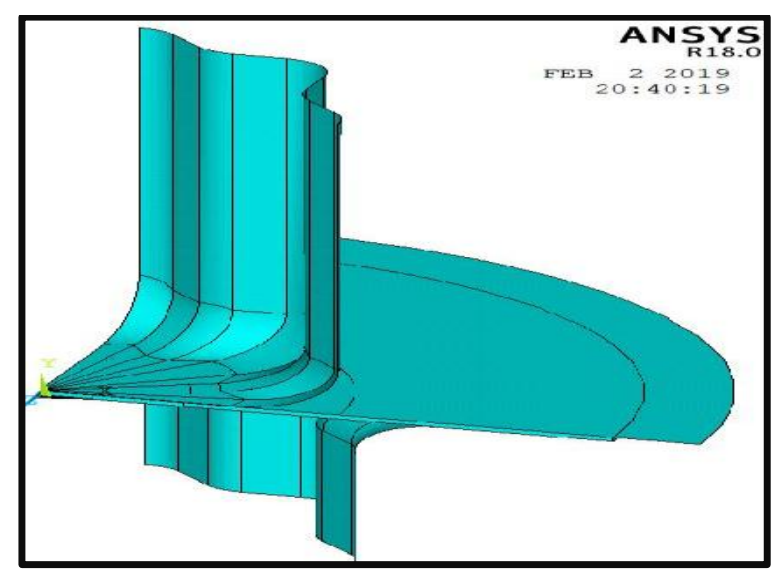

Figure 1: The geometry of the tool used

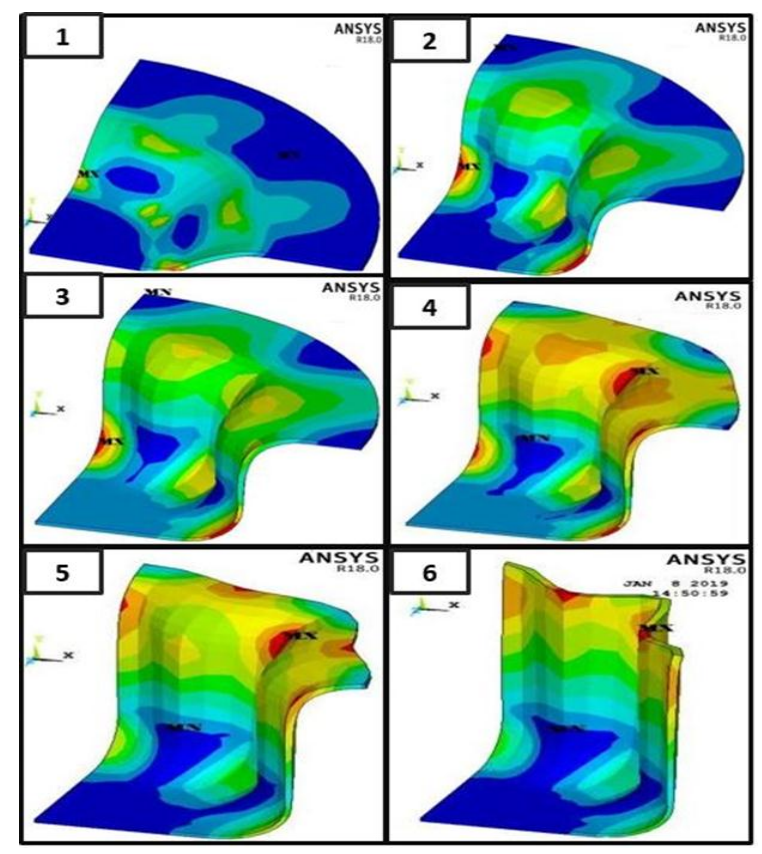

Figure 2: The Sequential stages of producing the astral cup using the numerical simulation 


\section{Experimental Procedure}

Deep drawing operation was done to obtain the astral cups by mounting deep drawing tool on the universal testing machine as shown in Figures 3 and 4 . The testing machine type (WDW-200E) which has a capacity of (200KN) was used. The deep drawing experiments were done by using the astral punch with dimensions $(41.5 \mathrm{~mm} \times$ $34.96 \mathrm{~mm})$, die with different dimensions $(43.52 \mathrm{~mm} \times 36.54 \mathrm{~mm}), \quad(43.7 \mathrm{~mm} \times 34.64 \mathrm{~mm})$, and $(43.95 \mathrm{~mm} \times 36.81 \mathrm{~mm})$, wall corner radius of punch and die $\left(R_{c p}\right.$ and $\left.R_{c d}=4 \mathrm{~mm}\right)$, and punch and die profile radius $\left(R_{p}\right.$ and $\left.R_{d}=6 \mathrm{~mm}\right)$ as shown in Figure 5. Low carbon steel alloy (0.08 $\%$ C) has $(0.7 \mathrm{~mm})$ thickness and diameter of $(80 \mathrm{~mm})$ for cold drawing process was selected in the present study to perform the experimental procedure. Some experiments were performed to study the influence of the radial clearance on drawing load and strain and thickness distribution over the side wall. The major axis corner and the minor axis corner of the completely drawn cup, four types of radial clearance equal to (1.1to, $1.2 t_{\circ}$, and 1.3to ) and drawing speed $(\mathrm{v}=100$ $\mathrm{mm} / \mathrm{min}$ ) were used. In order to measure the distribution of strain on the cup during deep drawing operation, the square grids with dimensions $(2 \times 2 \mathrm{~mm})$ were printed on a circular blank sheet using a laser machine as shown in
Figure 6A. After completion of the deep drawing experiments, the distortion was in the longitudinal and perimeter direction of the square block on the cup wall and no deformation is in the base of the cup as shown in Figure 6B. The completely drawn cup was divided into two parts using the wire cut machine to measure the thickness distribution as shown in Figure 7. The digital micrometer was used to measure the thickness distribution along the side wall, the minor corner axis, and the major corner. The change in radial and circumference dimensions of the grid square on the completely drawn cup is measured using tool microscope to determine the radial and hoop strain respectively. Figure 8 shows the samples of completely drawn cups with different radial clearance. Thickness strain and the radial strain was calculated using the following equations (1) and (2), respectively and then hoop strain and effective strain by using equation (3) and (4).

$\epsilon_{t}=\ln \frac{t}{t_{0}}$

$\epsilon_{r}=\ln \frac{R}{R_{\circ}}$

$\epsilon_{\theta}=-\left(\epsilon_{r}+\epsilon_{t}\right)$

$\epsilon_{e f f}=\sqrt{\frac{2}{3}\left(\epsilon_{\mathrm{r}}^{2}+\epsilon_{\theta}^{2}+\epsilon_{t}^{2}\right)}$

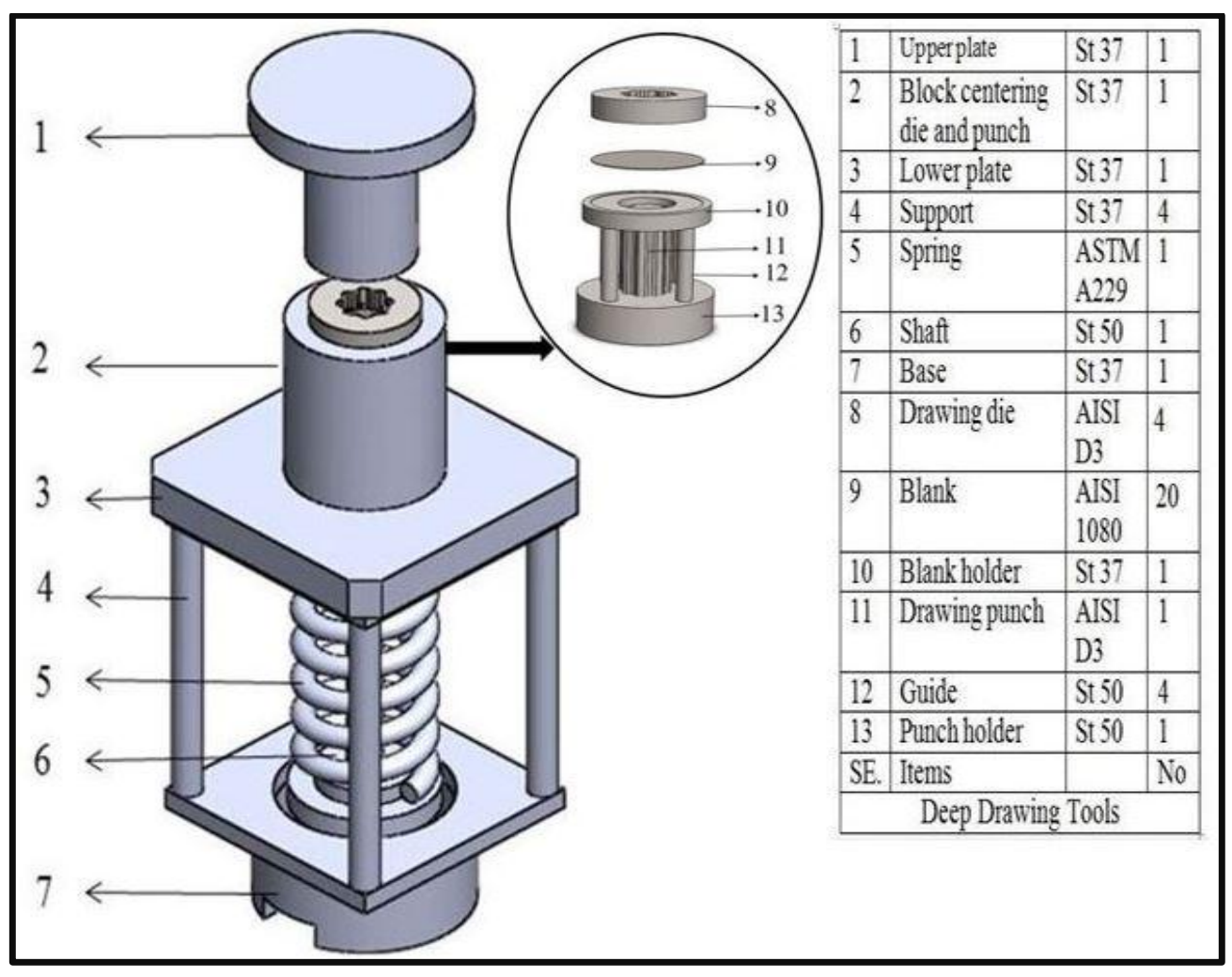

Figure 3: Schematic shows the deep drawing tool used 


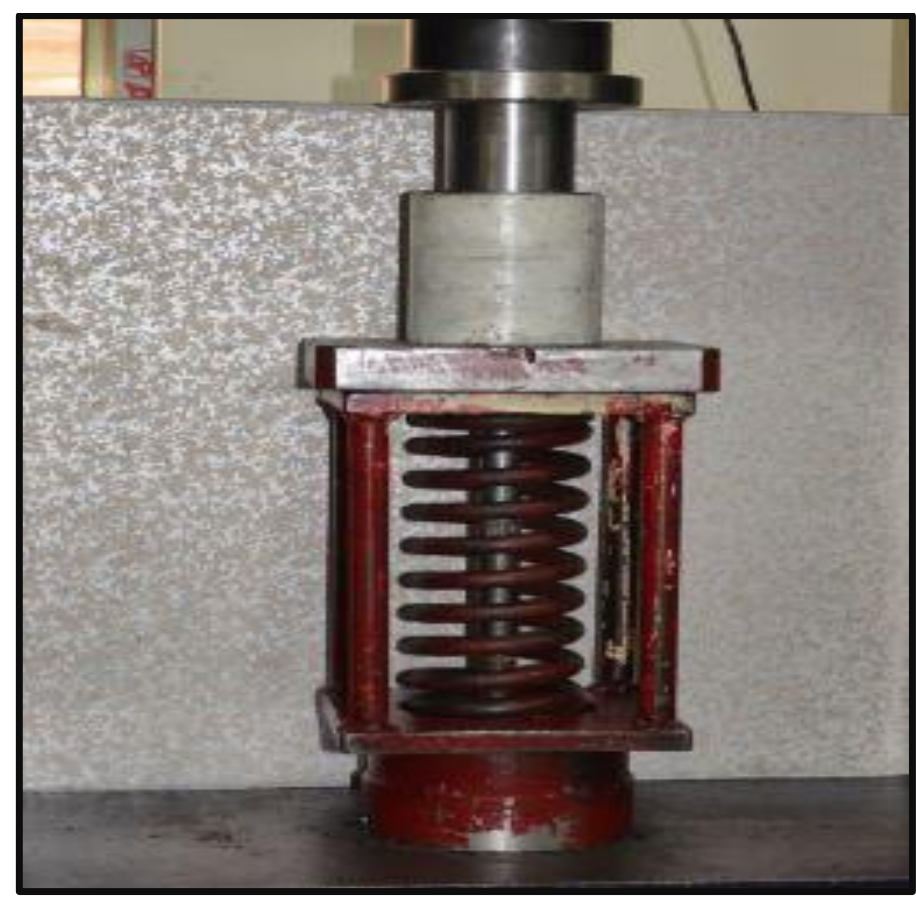

Figure 4: Photograph shows deep drawing tool used



Figure 5: The astral punch and die used in the deep drawing process

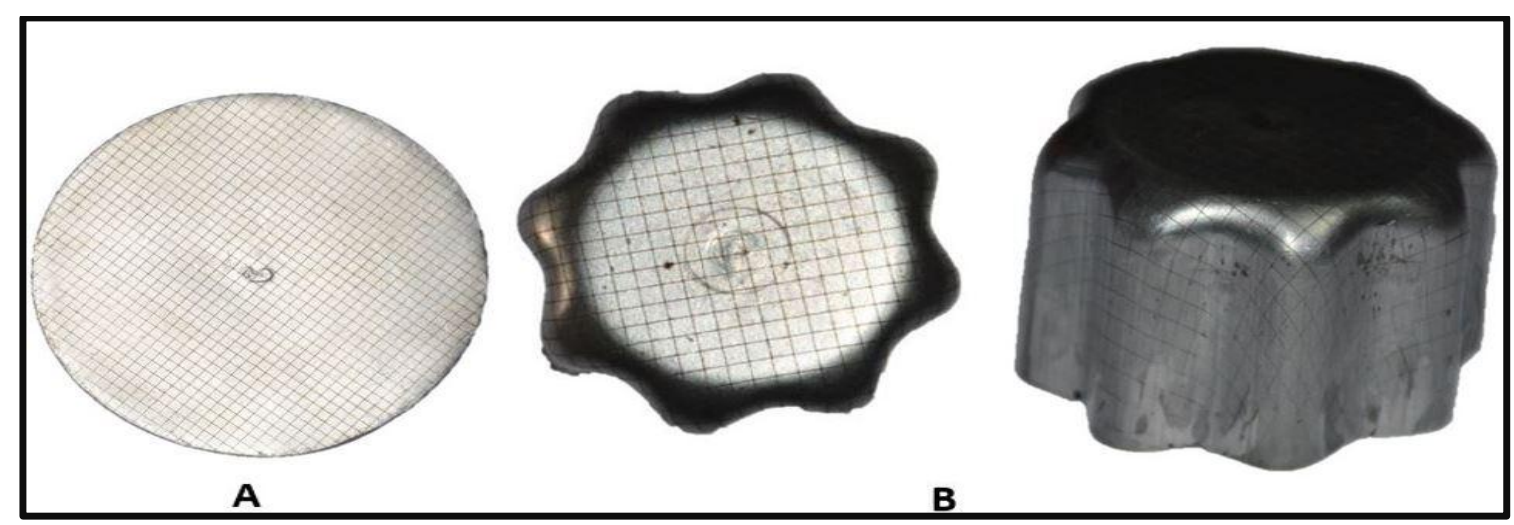

Figure 6: (A) The blank with square grids, (B) distortion of grid square at the cup wall and bottom 




Figure 7: The sample of divided cups.

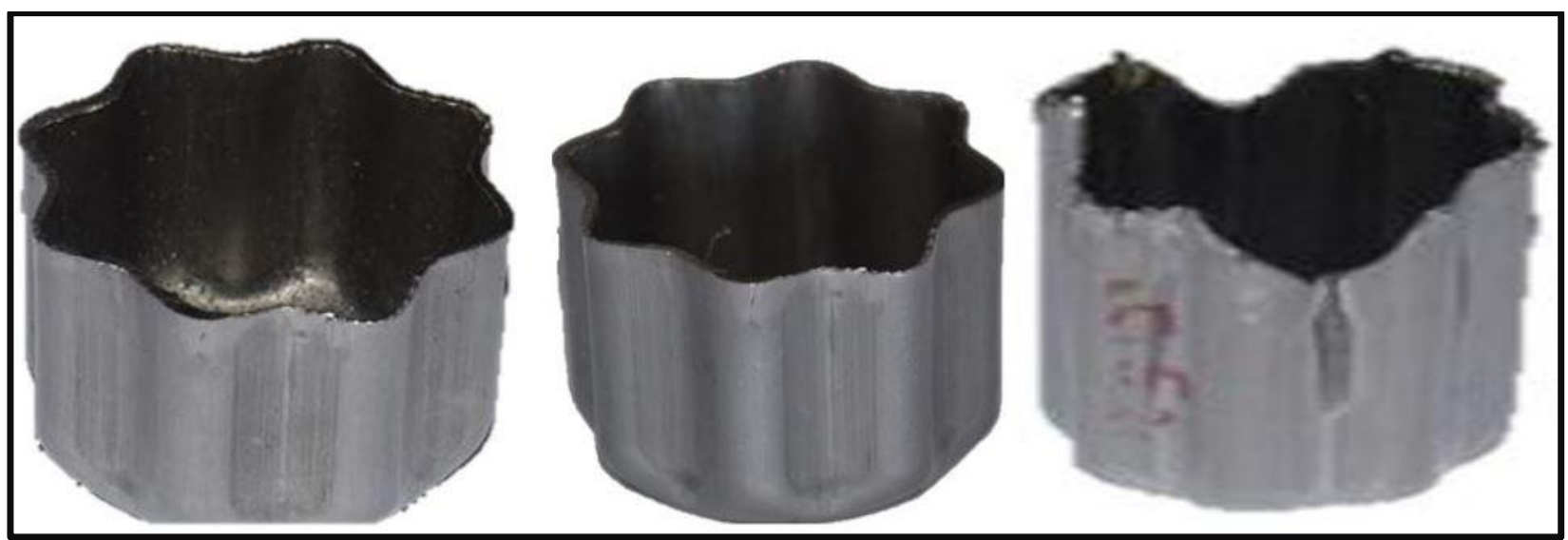

Figure 8: The astral cup produced with different radial clearance

\section{Results and Discussion}

Figure 9 illustrates the punch loads under different radial clearances using numerical simulation and experimental work. It is clear from this figure that at the beginning of the drawing operation, the drawing load is taken up until the maximum value reaches it. Then, it starts slowly decreasing until the drawing operation is completed. The drawing load decreases with increasing clearance as the maximum value of the drawing load recorded with a radial clearance equal (1.1to), while the lowest value of the drawing load recorded with clearance (1.3to).

Figure 10 indicates the difference in the distribution of the thickness after drawing operation along the major and minor, and the side wall of the drawn cup under various radial clearances using the numerical simulation and experimental work. From this figure, it can be observed that the thickness was measured from the center of the cup until the end of the cup. It was found in the area under the flat face of the punch. There is no change in the thickness due to the friction which plays an important role to overcome any distortion in this region. In the cup curling region, the thinning begins and its maximum value is recorded with the radial clearance $\left(1.1 t_{\circ}\right)$ at the minor axis. The thickness then begins to increase until the maximum value is reached at the end of the cup recorded with clearance $\left(1.3 t_{\circ}\right)$ at the side wall. It can be observed from the figure a process of a squeeze in the wall that occurred with the radial clearance $\left(1.1 t_{0}\right)$ due to the difficulty of the flow of the metal to be exposed to maximum tensile stress.

Figure 11 refers to the influence of radial clearance on effective strain along the major and minor axis, and the side wall of the drawn cup using the numerical simulation and experimental work. The effective strains were measured from the center of the cup until the throat of the cup. From this figure, it can be observed that the effective strains equal to zero in the contact area of the flat surface of the punch with the blank sheet. After exceeding this area, the effective strains are increased until the top of the cup and the maximum value was recorded with the clearance $\left(1.1 t_{0}\right)$ at the minor axis. This is due to that this area has been exposed to the highest concentration of the stresses compared to other areas, especially with clearance $\left(1.1 t_{0}\right)$, while the 
lowest value was recorded with clearance (1.3to) at the side wall.

Figure 12 shows the influence of radial clearance on effective stress along the side wall and major and minor axis of the drawn cup using the numerical simulation. The effective stresses were measured from the center of the cup until the top of the cup. It can be seen from this figure that the stresses are increasing from the area of curvature of the cup to the top of the cup and recorded the maximum values with the clearance of $\left(1.1 t_{0}\right)$ at the minor axis. This is due to that this area has been exposed to the highest tension of the rest of the areas with clearance (1.1 $\left.t_{\circ}\right)$, while recorded the least stresses with clearance (1.3to

Figure 13 illustrates the influence of radial clearance on cup height by analysis and experimentation. It can be seen from this figure that the cup height increases with the decrease the radial clearance value due to the increase in the metal due to severe stretching of metal with the small radial clearance, which contributes to an increase in the height of the cup both analysis and experiments. Table 1 shows the maximum values for recorded results for practical tests and numerical simulators.

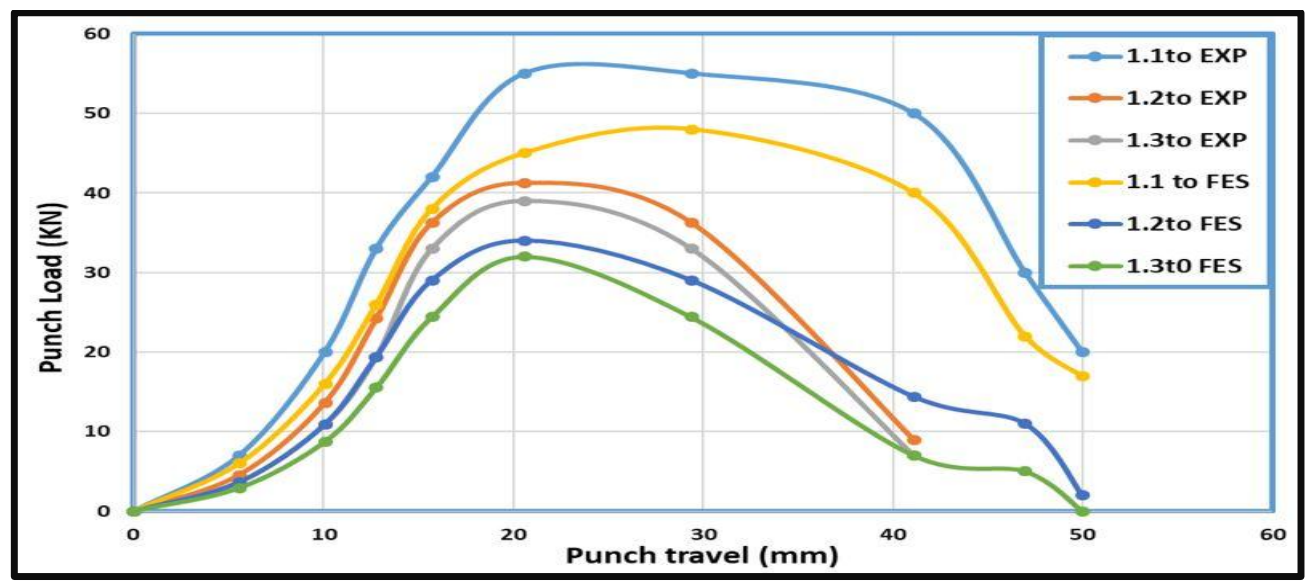

Figure 9: The relationship between punch loads and punch travel under different radial clearances

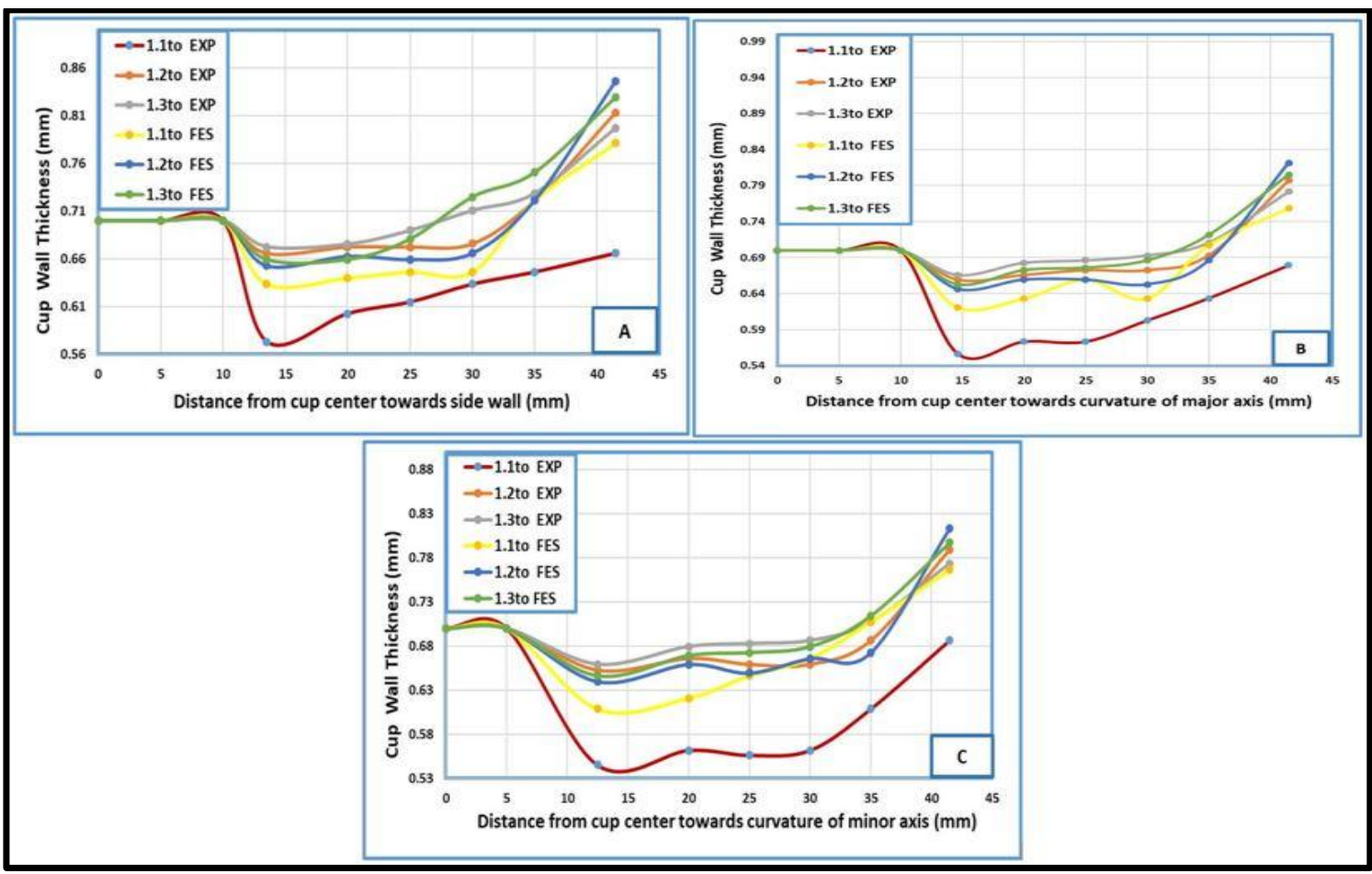

Figure 10: The difference of the distribution of the thickness after drawing operation under various radial clearances 


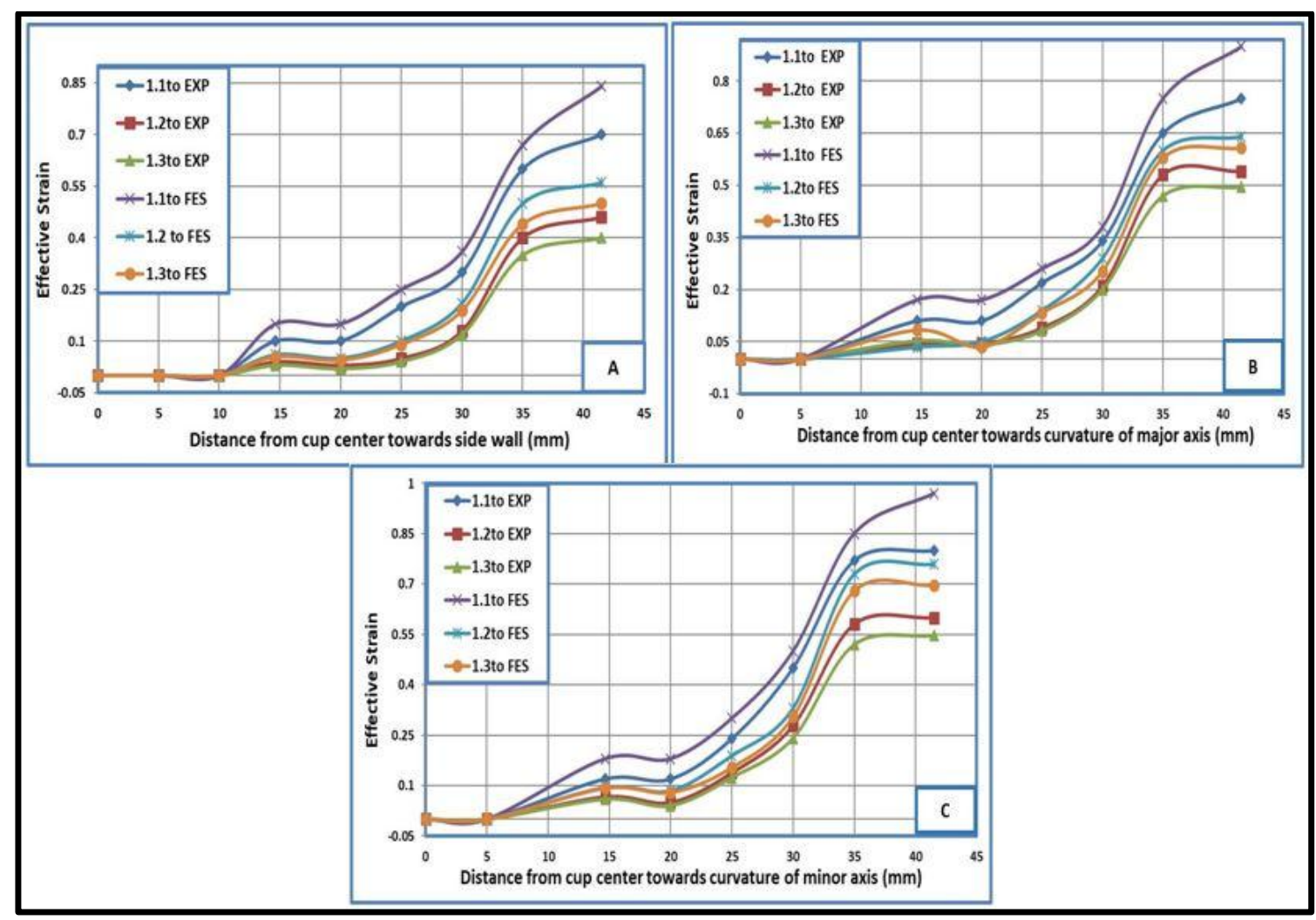

Figure 11: The influence of radial clearance on the effective strain.

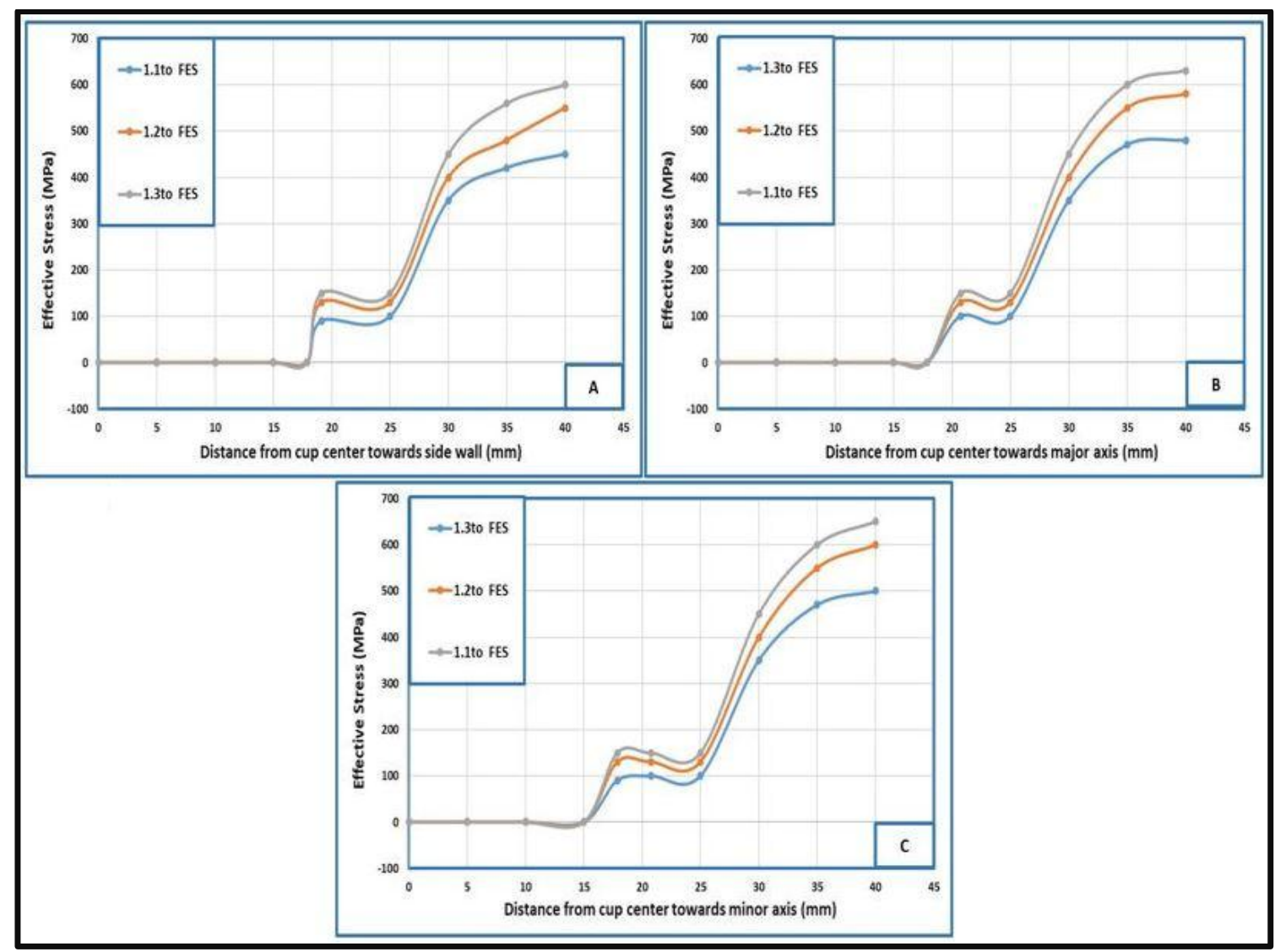

Figure 12: The influence of radial clearance on effective stress. 


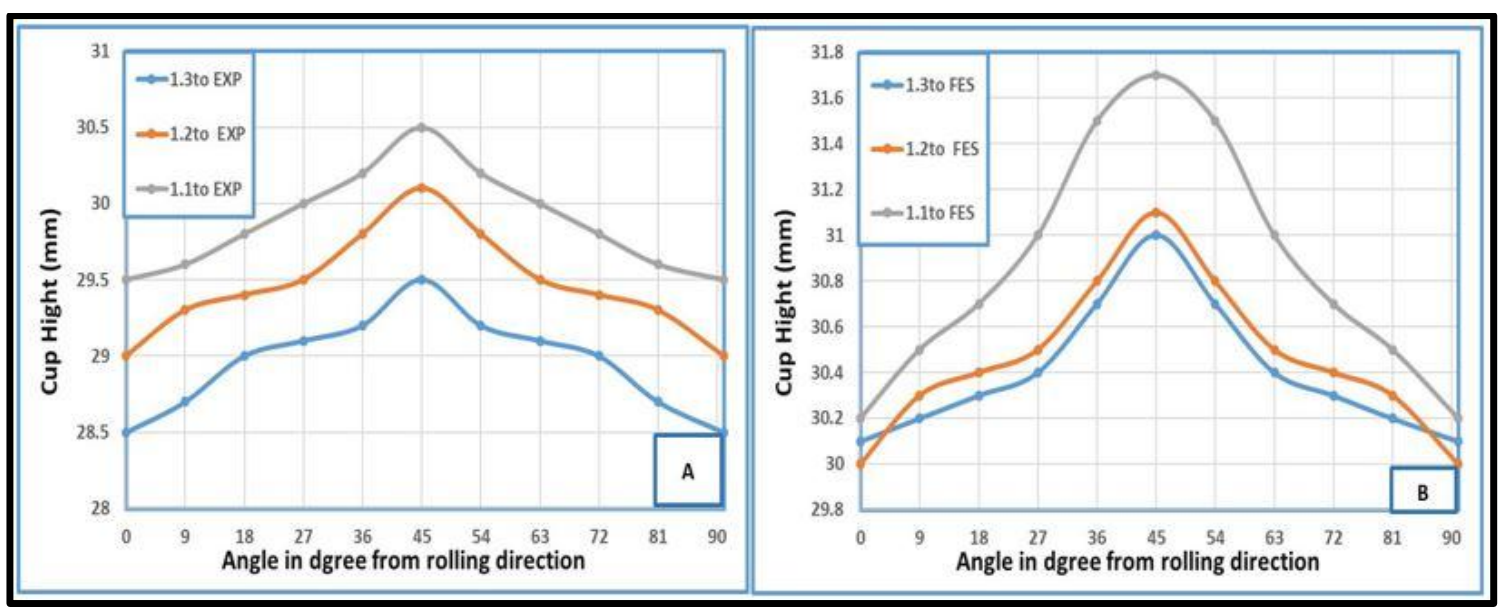

Figure 13: The influence of radial clearance on cup height by analysis and experimental

Table 1: The maximum values for recorded results for the practical tests and numerical simulation

\begin{tabular}{llllcccccc}
\hline \hline $\begin{array}{l}\text { Radial } \\
\text { Clearance }\end{array}$ & \multicolumn{2}{c}{$\begin{array}{c}\text { drawing load) } \\
(\mathrm{KN})\end{array}$} & \multicolumn{2}{c}{$\begin{array}{c}\text { max effective } \\
\text { strain }(\mathrm{mm})\end{array}$} & $\begin{array}{c}\text { cup height } \\
(\mathrm{mm})\end{array}$ & $\begin{array}{c}\text { Max thinning } \\
\%\end{array}$ & $\begin{array}{c}\text { max effective stress } \\
(\mathrm{MPa})\end{array}$ \\
\cline { 2 - 10 } & EXP & FES & EXP & FES & EXP & FES & EXP & FES & FES \\
\hline $1.1 t_{\circ}$ & 55 & 48 & 0.812 & 0.973 & 30.511 & 31.723 & 13.064 & 22.311 & 674 \\
\hline $1.2 t_{\circ}$ & 41.3 & 34 & 0.632 & 0.765 & 30.143 & 31.534 & 6.8323 & 8.607 & 602 \\
\hline $1.3 t_{\circ}$ & 39 & 23 & 0.547 & 0.697 & 29.512 & 31.132 & 5.821 & 7.688 & 511 \\
\hline
\end{tabular}

\section{Conclusions}

1-The drawing load decreases with increasing radial clearance as the maximum value of the drawing load $(55 \mathrm{KN})$ recorded with a radial clearance equal $\left(1.1 t_{\circ}\right)$, while the lowest value of the drawing load $(39 \mathrm{KN})$ recorded with clearance (1.3to) experimentally. This is due to the effect of bending intensity with a radial clearance equal $\left(1.1 t_{\circ}\right)$ compared to the little effect of bending with clearance $\left(1.3 t_{\circ}\right)$.

2-The thinning at cup corner increases with decreasing of the radial clearance and the maximum value of thinning $(28 \%)$ was recorded with the clearance (1.1to) at the minor axis region.

3 -The process of a squeeze in the wall occurred with the radial clearance $\left(1.1 t_{0}\right)$.

4-The maximum value of the effective stress is $(670 \mathrm{MPa})$ and effective strain is $(0.978)$ when using the clearance $\left(1.3 t_{0}\right)$.

5-The best distribution of the thickness, strains and the stresses along the cup wall were when using the clearance $\left(1.2 t_{\circ}\right)$.

6-The height of the cup increases with the decrease the radial clearance as the maximum value of the cup height $(31.723 \mathrm{~mm})$ recorded with a radial clearance equal (1.1to) due to severe stretching of metal with the small radial clearance, which contributes in an increase in the height of the cup both analysis and experiments.

\section{References}

[1] N.S.M. Namer, S.A. Nama, and J.W. Thabit, "Numerical and Experimental Study on Deep Drawing Process for AA2024-T4 Sheet," Journal of Applied and Experimental Mechanics, Vol. 1, Issue. 1, pp. 1-9, 2015.

[2] R. Padmanabhan, M.C. Oliveira, J.L. Alves, and L.F. Menezes, "Influence of process parameters on the deep drawing of stainless steel," Journal of Materials Processing Technology, Vol.43, pp. 1062 - 1067, 2007.

[3] H. Zein, M. El-Sherbiny, M. Abd-Rabou, and M. El Shazly, "Effect of Die Design Parameters on Thinning of Sheet Metal in the Deep Drawing Process," American Journal of Mechanical Engineering, Vol.1, No. 2, pp. 2029, 2013.

[4] A.C.S. Reddy, S. Rajesham, P.R. Reddy, and T.P. Kumar, "An experimental study on the effect of process parameters in deep drawing using Taguchi technique," International Journal of Engineering, Science and Technology, Vol.7, No. 1, pp. 21-32, 2015.

[5] H.A Ameen, and O.H. Abdulridha, "Effect of Clearance and Blank Thickness on Stress Distribution in Elliptical Deep Drawing without Blank Holder using ANSYS," International Journal of Engineering Research \& Technology, Vol.50, Nol.5, Issue.1, pp. 360-366, 2016.

[6] W.K. Jawed and S.S. Dawood "Drawing of Hexagonal Cup," Eng. \&Tech. Journal, Vol.34, No. 7, pp. 1445-1456, 2016.

[7] A.I.O. Zaid and F.A. Hashim, "Effect of Punch and Die Profile Radii on Deep Drawing of Galvanized Steel," International Journal of Applied Research in Mechanical Engineering, Vol.1, Issue-1, pp. 17-23, 2017. 
[8] M. Mahmoodi and H. Sohrabi, "Using the Taguchi Method for Experimental and Numerical Investigations on the Square-Cup Deep-Drawing Process for Aluminum/Steel Laminated Sheets," Mechanics of Advanced Composite Structures, Vol, pp. 169-177, 2017.

[9] A.K. Choubey, G. Agnihotri and C. Sasikumar, "Experimental and mathematical analysis of simulation results for sheet metal parts in deep drawing," Journal of Mechanical Science and Technology, Vol. 31, No. 9, pp. 4215-4220, 2017.

[10] S.J.H. Nejad1, R. Hasanzadeh, A. Doniavi, and V. Modanloo, "Finite element simulation analysis of laminated sheets in deep drawing process using response surface method," International Journal of Advanced Manufacturing Technology, Vol. 4, Nol.1, pp. 1-6, 2017. 